\title{
Macular hole surgery: an analysis of risk factors for the anatomical and functional outcomes with a special emphasis on the experience of the surgeon
}

This article was published in the following Dove Press journal:

Clinical Ophthalmology

13 June 2017

Number of times this article has been viewed

Teresa M Jenisch'

Florian Zeman ${ }^{2}$

Michael Koller ${ }^{2}$

David A Märker ${ }^{\prime}$

Horst Helbig'

Wolfgang A Herrmann ${ }^{1,3}$

'Department of Ophthalmology,

${ }^{2}$ Centre for Clinical Studies,

University Hospital Regensburg,

${ }^{3}$ Department of Ophthalmology,

St John of God Hospital, Regensburg,

Germany
Correspondence: Teresa M Jenisch Department of Ophthalmology, University Hospital Regensburg, Franz-Joseph-Strauss Alle II, 93053

Regensburg, Germany

$\mathrm{Tel}+4917622145384$

Fax +49 94I 504329 II

Email t.jenisch@outlook.de
Purpose: The aim of this study was to evaluate risk factors for the anatomical and functional outcomes of macular hole $(\mathrm{MH})$ surgery with special emphasis on the experience of the surgeon. Methods: A total of 225 surgeries on idiopathic MHs (IMHs) performed by 6 surgeons with a mean follow-up period of 20.5 months were reviewed in this retrospective study. Outcome parameters focused on IMH closure, complications and visual acuity improvement. The results of $\mathrm{MH}$ surgeries performed by experienced surgeons were compared to those of surgeons in training.

Results: The average MH size was $381 \mu \mathrm{m}$ (standard deviation [SD]=168). Brilliant blue $\mathrm{G}$ (BBG) for internal limiting membrane (ILM) staining was used in 109 (48\%) eyes and indocyanine green (ICG) in $116(52 \%)$ eyes. As endotamponade, 20\% SF6 was used in 38 (17\%) cases, $16 \% \mathrm{C} 2 \mathrm{~F} 6$ in $33(15 \%)$ cases and 16\% C3F8 in 154 (68\%) cases. IMH closure was achieved in 194 eyes (86\%). Mean preoperative visual acuity was 0.84 logarithm of the minimum angle of resolution ( $\log \mathrm{MAR} ; \mathrm{SD}=0.29$, range: $0.3-1.5$ ); surgery led to a mean improvement of 0.40 $(\mathrm{SD}=0.37) \log \mathrm{MAR}$. Although the MH closure rate was the same using BBG or ICG for ILM peeling, visual acuity improvement was better in eyes peeled with BBG compared to eyes peeled with ICG (log MAR: BBG: 0.38 [95\% CI: 0.32, 0.44] vs ICG: 0.48 [95\% CI: 0.42, 0.54], $P=0.029)$. Surgeons with previous experience in vitreoretinal surgery of $\geq 6$ years achieved better visual outcomes compared to surgeons with 0-3 years of experience, regardless of the MH size, preoperative visual acuity, time to follow-up or dye used for ILM peeling ( $0-3$ years $[0.27, \Delta \log$ MAR] vs $\geq 6$ years [0.43, $\Delta \log$ MAR], $P=0.009)$.

Conclusion: Our results indicate that vitrectomy with ILM peeling performed by non-experienced surgeons is a safe procedure leading to good anatomical and functional results. Very experienced surgeons may achieve even better functional outcomes.

Keywords: idiopathic macular hole, vitrectomy, ILM peeling, intraocular tamponade, brilliant peel

\section{Introduction}

Idiopathic macular hole (IMH) is a condition that usually affects patients aged $>50$ years, resulting in poor central vision. The prevalence is $3 / 1,000$ with a female predominance. ${ }^{1,2}$

Since the first description of vitreoretinal surgery for macular holes (MHs) by Kelly and Wendel, ${ }^{3}$ operation methods for MH surgery continue to undergo refinement. Vitrectomy, internal limiting membrane (ILM) peeling using dyes such as trypan blue (TB), brilliant blue $\mathrm{G}$ (BBG) and indocyanine green (ICG) and gas endotamponade have become the most frequently carried out procedures. ${ }^{4}$ Surgical intervention may lead to significant 
vision improvement and favorable anatomical closure rates in $>90 \%$ of the cases. ${ }^{5-13}$ Shorter duration of symptoms, earlier stage of $\mathrm{MH}$, better preoperative visual acuity and younger patient age have been reported to be significantly associated with better surgical results. ${ }^{14-20}$ Recent studies also showed the influence of the structure of the external limiting membrane (ELM) and the photoreceptor ellipsoid zone (EZ) before and after $\mathrm{MH}$ surgery on the functional outcome. ${ }^{21}$

However, after surgical intervention, some MHs still remain open or even reopen after several years. ${ }^{22-25}$

MH surgery can be accompanied by a broad spectrum of intra- and postoperative complications, including retinal tears and detachments, iatrogenic MHs, macular edema, postoperative endophthalmitis and development of progressive cataract, compromising the functional outcome of surgery. ${ }^{26-28}$

Surgical success depends on microsurgical skills such as spatial coordination and precision of movement that largely depend on the experience of the surgeon..$^{29}$

The aim of this study was to evaluate the anatomical and functional outcomes of $\mathrm{MH}$ surgery at a tertiary care academic center with special emphasis on the experience of the surgeon.

\section{Materials and methods Study design and inclusion and exclusion criteria}

This study was designed as a retrospective cohort study. In total, we evaluated $\mathrm{MH}$ surgeries of 6 surgeons with variable levels of experience in vitreoretinal surgery. The study was conducted according to the tenets of the Declaration of Helsinki. The ethics committee of the University of Regensburg did not require an ethics approval and patient's consent to be sought for this study due to its retrospective nature, because all data were de-identified. Medical data were obtained by retrospective chart review of patients who underwent surgery for IMH at the Department of Ophthalmology, University of Regensburg Medical Centre, Regensburg, Germany, between January 2005 and December 2011. A total of 225 eyes of 225 patients with previous MH surgery for IMH were included. Inclusion criterion was the presentation of a full-thickness IMH. Eyes were excluded from the study if they had preexisting ocular diseases that could have adversely influenced the outcome of the surgery and all eyes with a history of ocular trauma. Moreover, all eyes with a history of ocular surgery except for cataract surgery were excluded. Preoperative chart data obtained included age of the patient, gender, preoperative best-corrected visual acuity (BCVA), lens status, visibility of an epiretinal membrane in preoperative optical coherence tomography (OCT) scans (Stratus
OCT [Carl Zeiss Meditec, Jena, Germany] or Spectralis OCT [Heidelberg Engineering, Heidelberg, Germany]), stage of $\mathrm{MH}$ according to the classification of $\mathrm{Gass}^{30}$ and diameter of the $\mathrm{MH}$ at presentation. The maximum $\mathrm{MH}$ diameter was defined as the diameter of the aperture (6 radial line scans), and only the largest measurement was considered.

\section{Anatomical and functional outcomes}

The focus of the analysis was the rate of $\mathrm{MH}$ closure at the postoperative visit 6-8 weeks after surgery. MH closure was evaluated by OCT scans. $\mathrm{MH}$ closure was defined as reattachment of the edges of the hole to the retinal pigment epithelium or connection from the edge from side to side. The EZ was evaluated on postoperative OCT scans. Lens status and intraoperative or postoperative complications were taken from the patient's charts and the operative reports. Postoperative endophthalmitis, iatrogenic retinal breaks and retinal detachment were considered as intraoperative or postoperative complications. The BCVA at the last postoperative visit was assessed. Median postoperative follow-up was 20.5 months (range: 1-80 months).

\section{Surgical technique}

All eyes underwent $23 \mathrm{G}$ or $20 \mathrm{G}$ 3-port pars plana vitrectomy with ILM peeling and gas endotamponade. All surgeries were carried out applying an Alcon Accurus Unit (Alcon, Freiburg, Germany). The ILM was stained in all eyes with a vital dye. For this purpose, ICG with a concentration of $0.05 \%$ (ICGPulsion; Pulsion Medical Systems, Feldkirchen, Germany) or brilliant peel (brilliant peel; Geuder, Heidelberg, Germany) was used. Staining time ranged between 10 seconds and 20 seconds.

In all phakic eyes, pars plana vitrectomy was combined with clear corneal phacoemulsification and implantation of an intraocular lens.

All patients were encouraged to maintain a face-down position for at least 1 week after surgery.

\section{Surgeon characteristics}

In total, we included surgical interventions of 6 vitreoretinal surgeons. Due to the retrospective character of the study, each surgeon (number [n] 1-6) contributed a different number of $\mathrm{MH}$ surgeries ( $\mathrm{n} 1=36$ vs $\mathrm{n} 2=67$ vs $\mathrm{n} 3=34$ vs $\mathrm{n} 4=31$ vs $n 5=15$ vs n6=42). To describe the surgeon's individual level of experience, operative reports of each surgeon were evaluated. The number of years of previous experience in vitreoretinal surgery of the surgeon was assigned to each $\mathrm{MH}$ intervention. Finally, we classified subgroups from 0 to $>6$ years of previous experience in vitreoretinal surgery: 
group I ( $0-3$ years of previous experience in vitreoretinal surgery, $n=43$ ), group II (4 years of experience, $n=41$ ), group III ( 5 years of experience, $n=44$ ) and group IV ( $\geq 6$ years of experience, $n=97$ ). We compared very non-experienced surgeons (group I) with very experienced surgeons (group IV). Groups II and III were created to detect a potential gain of experience influencing the results to demonstrate a prospective learning curve.

\section{Statistical analyses}

Data were collected in an SPSS spreadsheet and were analyzed with SPSS statistical software system version 20.0. A $P$-value of $<0.05$ was considered statistically significant. All visual acuity values were converted to the logarithm of the minimum angle of resolution ( $\log$ MAR) equivalent for statistical analysis. Patient characteristics were summarized by means of mean values (standard deviation, SD) and ranges (minimum to maximum) for continuous variables, as well as by frequency counts and percentages for categorical data. For a comparison of 2 continuous variables, Student's $t$-test was used, while comparisons between categorical variables were performed by the use of the exact unconditional Pearson's chi-squared statistic (z-pooled). For the comparison of changes in log MAR between groups, analysis of covariance (ANCOVA) was used including group as the main factor and the baseline value of $\log$ MAR as a covariate to adjust for baseline differences. Associations between patient/surgery characteristics and closure of the $\mathrm{MH}$ were described using logistic regression analysis. Univariable and multivariable logistic regression models were calculated, while the multivariable model contained only variables with a $P$-value of $<0.05$ in the univariable model.

\section{Results \\ Patient characteristics}

A total of 225 eyes of 225 patients, aged between 48 and 85 years (mean $=70[\mathrm{SD}=7]$ ), were included in this study. Of 225 patients, 73 (32\%) were males and $181(80 \%)$ eyes undergoing surgery were phakic. In 36 eyes $(16 \%)$, an epiretinal membrane was visible on the OCT images before surgery. The mean preoperative visual acuity was $0.84 \mathrm{log}$ MAR ( $\mathrm{SD}=0.29$, range: $0.3-1.5$ ). On average, the size of the MHs was $381 \mu \mathrm{m}(\mathrm{SD}=168$, range: $50-1,185 \mu \mathrm{m})$. All baseline characteristics are presented in Table 1.

\section{Operation methods, outcome and postoperative complications}

A $20 \mathrm{G}$ vitrectomy was performed in $177(79 \%)$ eyes and $23 \mathrm{G}$ vitrectomy in $48(21 \%)$ eyes. Brilliant peel for ILM peeling was used in $109(48 \%)$ eyes and ICG in $116(52 \%)$ eyes. As intraocular tamponade, $20 \%$ SF6 was used in 38 (17\%) eyes, 16\% C2F6 in 33 (15\%) eyes and 16\% C3F8 in $154(68 \%)$ eyes. Mean operation time was 63 minutes ( $\mathrm{SD}=19$, range: $24-117$ minutes), while non-experienced surgeons needed more time than experienced surgeons (group I vs group IV: 75.88 minutes [SD=17.68] vs 53.41 minutes [SD=13.60]; Table 2).

Table I Demographic and clinical patient characteristics

\begin{tabular}{|c|c|c|c|c|c|c|}
\hline \multirow[t]{2}{*}{ Characteristics } & \multicolumn{5}{|c|}{ Years of previous experience in vitreoretinal surgery } & \multirow[t]{2}{*}{$P$-value } \\
\hline & $\begin{array}{l}\text { All } \\
(n=225)\end{array}$ & $\begin{array}{l}0-3 \text { years } \\
(n=43)\end{array}$ & $\begin{array}{l}4 \text { years } \\
(n=4 I)\end{array}$ & $\begin{array}{l}5 \text { years } \\
(n=44)\end{array}$ & $\begin{array}{l}\geq 6 \text { years } \\
(n=97)\end{array}$ & \\
\hline Age (years) & $70(\mathrm{SD}=7)$ & $70(S D=7)$ & $70(S D=5)$ & $70(S D=7)$ & $69(\mathrm{SD}=7)$ & $0.822^{\mathrm{A}}$ \\
\hline Gender (male), n (\%) & $73(32)$ & $10(23)$ & $12(29)$ & $16(36)$ & $35(36)$ & $0.434^{c}$ \\
\hline \multicolumn{7}{|l|}{ Side, n (\%) } \\
\hline Left & II2 (50) & $19(44)$ & $18(44)$ & $24(54.5)$ & $51(53)$ & $0.613^{c}$ \\
\hline Right & $113(50)$ & $24(56)$ & $23(56)$ & $20(46.5)$ & $46(47)$ & \\
\hline \multicolumn{7}{|l|}{ Stage of macular hole*, n (\%) } \\
\hline II & II $17(52)$ & $23(54)$ & $2 \mathrm{I}(5 \mathrm{I})$ & $17(39)$ & $56(58)$ & $0.292^{c}$ \\
\hline III & $72(32)$ & $13(30)$ & $15(37)$ & $15(34)$ & $29(30)$ & \\
\hline IV & $36(16)$ & $7(16)$ & $5(12)$ & $12(27)$ & $12(12)$ & \\
\hline Maximum size of hole $(\mu \mathrm{m})$ & $381(S D=168)$ & $418(S D=190)$ & $385(\mathrm{SD}=145)$ & $432(S D=163)$ & $340(S D=161)$ & $0.007^{\mathrm{A}}$ \\
\hline \multicolumn{7}{|l|}{ Lens status, $\mathrm{n}(\%)$} \\
\hline Phakic & $|8|(80)$ & $34(79)$ & $32(78)$ & $38(86)$ & $77(79)$ & $0.74 I^{c}$ \\
\hline Pseudophakic & $44(20)$ & $9(2 I)^{\prime}$ & $9(22)$ & $6(14)$ & $20(2 I)$ & \\
\hline Epiretinal membrane (OCT), n (\%) & $36(16)$ & $3(7)$ & $9(22)$ & $8(18)$ & $16(17)$ & $0.277^{C}$ \\
\hline Visual acuity before surgery (log MAR) & $0.84(\mathrm{SD}=0.29)$ & $0.9(\mathrm{SD}=0.28)$ & $0.87(\mathrm{SD}=0.3)$ & $0.9(\mathrm{SD}=0.27)$ & $0.78(\mathrm{SD}=0.3)$ & $0.04 I^{\mathrm{A}}$ \\
\hline
\end{tabular}

Notes: Data are presented as n (\%) or mean (SD). ${ }^{A}$ Represents ANCOVA, ${ }^{C}$ represents Pearson's chi-squared test. *Classification according to Gass. ${ }^{30}$

Abbreviations: ANCOVA, analysis of covariance; log MAR, logarithm of the minimum angle of resolution; MH, macular hole; OCT, optical coherence tomography; $\mathrm{SD}$, standard deviation. 
Table 2 Surgery and complications

\begin{tabular}{|c|c|c|c|c|c|}
\hline & All $(n=225)$ & $0-3$ years $(n=43)$ & 4 years $(n=4 I)$ & 5 years $(n=44)$ & $\geq 6$ years $(n=97)$ \\
\hline Follow-up (months) & $20.5(\mathrm{SD}=19)$ & $32(\mathrm{SD}=23)$ & $22(S D=19)$ & $14(S D=12)$ & $24(S D=18)$ \\
\hline Operation time (minutes) & $63(\mathrm{SD}=19)$ & $76(S D=18)$ & $70(S D=19)$ & $66(S D=19)$ & $53(S D=14)$ \\
\hline \multicolumn{6}{|l|}{ Dye, n (\%) } \\
\hline ICG & $116(52)$ & $43(100)$ & $15(37)$ & $9(20.5)$ & $49(50.5)$ \\
\hline BBG & $109(48)$ & 0 & $26(63)$ & 35 (79.5) & $48(49.5)$ \\
\hline \multicolumn{6}{|l|}{ Incision size, n (\%) } \\
\hline $20 \mathrm{G}$ & 177 (79) & $43(100)$ & $31(76)$ & $24(54.5)$ & $79(8 I)$ \\
\hline $23 \mathrm{G}$ & $48(2 I)$ & 0 & $10(24)$ & $20(45.5)$ & $18(19)$ \\
\hline \multicolumn{6}{|l|}{ Tamponade, n (\%) } \\
\hline SF6 & $38(17)$ & $15(35)$ & $5(12)$ & I (2) & $17(18)$ \\
\hline $\mathrm{C} 2 \mathrm{~F} 6$ & $33(15)$ & $8(19)$ & $4(10)$ & $8(18)$ & $13(13)$ \\
\hline $\mathrm{C} 3 \mathrm{~F} 8$ & $154(68)$ & $20(47)$ & $32(78)$ & $35(80)$ & $67(69)$ \\
\hline Postoperative retinal detachment, n (\%) & $8(4)$ & $3(7)$ & $3(7)$ & 0 & $2(2)$ \\
\hline Kryocoagulation/laser retinopexy applied, n (\%) & $96(43)$ & $15(35)$ & $22(54)$ & $24(55)$ & $35(36)$ \\
\hline Persistent macular edema, n (\%) & $4(1.8)$ & I (2.3) & I (2.4) & $\mathrm{I}(2.3)$ & $I(I)$ \\
\hline Infection, reopening, iatrogenic MH, n (\%) & $0(0)$ & $0(0)$ & $0(0)$ & $0(0)$ & $0(0)$ \\
\hline
\end{tabular}

Note: Data are presented as $\mathrm{n}(\%)$ or mean (SD).

Abbreviations: BBG, brilliant blue G; ICG, indocyanine green; $\mathrm{MH}$, macular hole; SD, standard deviation.

\section{Intraoperative and postoperative complications}

Postoperative retinal detachment occurred in 8 eyes (3.6\%), whereas it occurred more often in groups I (7\%) and II (7.3\%) than in groups III $(0 \%)$ and IV $(2.1 \%)$.

In 96 (43\%) eyes, kryocoagulation and/or laser photocoagulation of retinal breaks or suspected retinal breaks was performed during surgery. There were no significant differences between the more experienced and the less experienced groups, but we could see a trend of more use of kryocoagulation and/or lasercoagulation within groups II and III, and less retinal treatments in groups I and IV.

Persistent macular edema occurred in 4 of 225 (1.8\%) eyes. In those cases, cataract surgery was performed simultaneously.

Furthermore, no case of endophthalmitis, no case of reopening of $\mathrm{MHs}$ and no case of iatrogenic $\mathrm{MH}$ were observed during the follow-up period (Table 2).

\section{Anatomical and functional outcomes}

In total, MH closure was achieved in 194/225 (86\%) eyes after primary surgery. Concerning the closure rates, there were no significant differences between the groups (Table 3).

Univariable logistic regression analyses were calculated with MH closure as the dependent variable and each of the risk factors mentioned earlier as independent variables. The only variables that yielded significant effects were the size of the $\mathrm{MH}$ (odds ratio [OR] $=2.36$ per $100 \mu \mathrm{m}, 95 \% \mathrm{CI}: 1.71$, $3.25, P<0.001)$ and stage of the MH $(P<0.01)$. Thus, the larger the hole, the greater the likelihood that the hole remained open. Multivariable logistic regression analysis showed that the size of the hole emerged as the only statistically significant risk factor with an OR of 2.36 per $100 \mu \mathrm{m}$ (95\% CI: 1.71, 3.25, $P<0.001$; Table 3).

The mean BCVA of all patients was $0.84(\mathrm{SD}=0.29$, range: $0.3-1.5) \log$ MAR before surgery. Median postoperative BCVA was obtained at 20.5 months after surgery with a mean postoperative visual acuity of $0.40(\mathrm{SD}=0.37) \log$ MAR. Visual acuity increased (difference of at least 0.2 units log MAR) in 143 eyes (64\%), remained unchanged in 49 eyes (24\%) and decreased in 10 eyes (4\%). Taking into account the different baseline characteristics (preoperative visual acuity, size of the $\mathrm{MH}$, follow-up time and dye), visual outcome of the surgeons in group I/surgeons with 0-3 years of experience compared to group IV/surgeons with $\geq 6$ years of experience was worse $(\Delta \log$ MAR [change of visual acuity after surgery: pre-log MAR-post$\log$ MAR]: $\triangle \log$ MAR: group I: vs $\triangle \log$ MAR: group IV: 0.27 $[0.18,0.37]$ vs 0.43 [0.37, 0.49], $P=0.009$; Table 4).

Table 3 Multivariable logistic regression models on $\mathrm{MH}$ closure

\begin{tabular}{ccllll}
\hline & $\mathbf{n}$ & $\begin{array}{l}\text { MH } \\
\text { closure }\end{array}$ & $\begin{array}{l}\text { No MH } \\
\text { closure }\end{array}$ & OR $(95 \%$ Cl) & P-value \\
\hline $\begin{array}{c}\text { Experience } \\
\text { 0-3 years }\end{array}$ & 43 & $36(84 \%)$ & $7(16 \%)$ & Reference category & \\
4 years & 41 & $35(85 \%)$ & $6(15 \%)$ & $1.23(0.31,4.82)$ & 0.768 \\
5 years & 44 & $36(82 \%)$ & $8(18 \%)$ & $1.02(0.28,3.74)$ & 0.976 \\
$\geq 6$ years & 97 & $87(90 \%)$ & $10(10 \%)$ & $1.00(0.29,3.43)$ & 0.993 \\
Size MH & 225 & 351 & 569 & $2.36(1.71,3.25)^{\mathrm{a}}$ & $<0.00 \mathrm{I}$ \\
& & $(\mathrm{SD}=145)$ & $(\mathrm{SD}=184)$ & & \\
\hline
\end{tabular}

Notes: Data are presented as $\mathrm{n}(\%)$ or mean (SD). ${ }^{\mathrm{a} e r} 100 \mu \mathrm{m}$. The odds ratio of each experience level refers to the reference category $0-3$ years.

Abbreviations: $\mathrm{Cl}$, confidence interval; $\mathrm{MH}$, macular hole; $\mathrm{OR}$, odds ratio; $\mathrm{SD}$, standard deviation. 
Table 4 Change of visual acuity after surgery (pre-log MAR-post$\log$ MAR)

\begin{tabular}{llll}
\hline & $\mathbf{n}$ & Mean $^{\mathrm{a}}(\mathbf{9 5 \%} \mathbf{C l})$ & $\boldsymbol{P}$-value vs reference \\
\hline Experience & & & \\
0-3 years & 37 & $0.27(0.18,0.37)$ & Reference \\
4 years & 37 & $0.38(0.28,0.48)$ & 0.144 \\
5 years & 39 & $0.43(0.31,0.56)$ & 0.052 \\
$\geq 6$ years & 89 & $0.43(0.37,0.49)$ & 0.009 \\
\hline
\end{tabular}

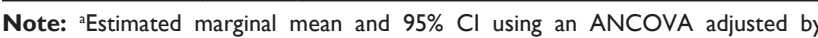
preoperative visual acuity, size of $\mathrm{MH}$, follow-up time and dye.

Abbreviations: ANCOVA, analysis of covariance; $\mathrm{Cl}$, confidence interval; log MAR, logarithm of the minimum angle of resolution; $\mathrm{MH}$, macular hole.

\section{Additional results}

Dye

ILM peeling with BBG led to a significant better visual outcome compared to ILM peeling with ICG (log MAR: BBG: 0.38 [95\% CI: 0.32, 0.44] vs ICG: 0.48 [95\% CI: $0.42,0.54], P=0.029)$.

\section{Epiretinal membrane}

Eyes with epiretinal membranes seen on the OCT scans before surgery had the same functional outcome as eyes without epiretinal membranes ( $\triangle \log$ MAR: 0.40 [SD $=0.37]$ vs 0.40 [SD=0.37], $P=0.97$ ).

\section{Incision size and retinal detachment}

Retinal detachment occurred in 8 of 225 patients. It was only observed in the $20 \mathrm{G}$ group $(5 \%, \mathrm{n}=8 / 177$ eyes), whereas it never occurred after $23 \mathrm{G}$ vitrectomy $(0 \%, \mathrm{n}=0 / 48$ eyes, $P=0.21)$.

Incision size and intraoperative complications

There was no higher risk $(P=0.32)$ for retinal tears using $20 \mathrm{G}$ instruments $(45 \%, 79 / 177)$ compared to $23 \mathrm{G}$ vitrectomy $(35 \%, 17 / 48)$.

Table 5 Multivariable logistic regression on restoration of macular structure $(n=164)$

\begin{tabular}{|c|c|c|c|c|c|}
\hline & $\mathbf{n}$ & Restoration & $\begin{array}{l}\text { No } \\
\text { restoration }\end{array}$ & $\begin{array}{l}\text { OR } \\
(95 \% \mathrm{Cl})\end{array}$ & $P$-value \\
\hline \multicolumn{6}{|l|}{ Experience } \\
\hline $0-3$ years & 24 & 7 (29\%) & I7 (7|\%) & $\begin{array}{l}\text { Reference } \\
\text { category }\end{array}$ & \\
\hline 4 years & 33 & 21 (64\%) & $12(36 \%)$ & $\begin{array}{l}0.34 \\
(0.09,1.28)\end{array}$ & 0.110 \\
\hline 5 years & 39 & $26(67 \%)$ & $13(33 \%)$ & $\begin{array}{l}0.16 \\
(0.04,0.6 I)\end{array}$ & 0.007 \\
\hline$\geq 6$ years & 68 & 38 (56\%) & 30 (44\%) & $\begin{array}{l}0.70 \\
(0.21,2.28)\end{array}$ & 0.548 \\
\hline Size MH & 164 & $\begin{array}{l}325 \\
(S D=136)\end{array}$ & $\begin{array}{l}506 \\
(S D=164)\end{array}$ & $\begin{array}{l}2.76 \\
(1.95,3.89)^{\mathrm{a}}\end{array}$ & $<0.001$ \\
\hline
\end{tabular}

Notes: Data are presented as $n(\%)$ or mean (SD). aPer $100 \mu \mathrm{m}$. The odds ratio of each experience level refers to the reference category $0-3$ years.

Abbreviations: $\mathrm{Cl}$, confidence interval; OR, odds ratio; $\mathrm{SD}$, standard deviation; $\mathrm{MH}$, macular hole.

\section{Integrity of the EZ}

Mean OCT follow-up was 6-8 weeks after surgery. Regarding $61 / 225$ eyes, due to a hardware exchange in the used OCT systems, we were unable to evaluate OCT images. In 92/164 eyes, the EZ was restored, whereas in 72/164 eyes no restoration was seen. We could find a positive correlation between restoration of the EZ and the surgeon's experience, but these results were not statistically significant (Table 5).

\section{Discussion}

This is the first study evaluating the surgeon's experience regarding the success of $\mathrm{MH}$ intervention.

Our data show that surgeons in training achieved good anatomical and functional results after MH surgery, whereas very experienced surgeons gained statistically significant better visual outcomes. Several studies have focused on the risk factors for non-closure after MH surgery. ${ }^{14-20}$ Size of the hole, poor preoperative BCVA and duration of symptoms emerged as statistically significant factors for non-closure of hole. Moreover, in recent studies, restoration of macular structure as the determining factor for postoperative functional outcome has been discussed. ${ }^{31}$ Operation methods including the need of ILM peeling with the use of different vital dyes (ICG, triamcinolone, TB, BBG) and different tamponades (air, gases, oil) and postoperative duration of face-down positioning have also been debated extensively. ${ }^{32,33} \mathrm{We}$ evaluated the complications and the success of MH intervention in relation to the surgeon's level of expertise in vitreoretinal surgery. Previous clinical studies have reported more complications occurring in cataract surgery during the surgeon's learning phase..$^{29,34}$ In MH surgery, in addition to the difficulties of pars plana vitrectomy, peeling of the delicate ILM represents a supplementary challenge for a non-experienced surgeon. Our data show that less experienced vitreoretinal surgeons achieved an acceptable closure rate of MHs (group I: 84\%) as compared to closure rates assessed in previous studies ranging from $55 \%$ to $100 \%$. $^{5-13}$

For MH surgery, the prevalence of iatrogenic breaks has been reported to be between $0 \%$ and $14.6 \%$, with postoperative retinal detachment occurring in $1.1 \%-14 \%$ of the cases. ${ }^{26,35-37}$ In our study, postoperative retinal detachments were seen in $3.6 \%$ in total as a result of new or missed retinal breaks. No case of endophthalmitis or reopening of $\mathrm{MH}$ was detected. During the study period, operation methods underwent refinement with regard to the use of dyes, incision sizes and tamponades. However, there was 
no significant correlation between hole closure and incision size and no correlation between the used dyes and gases and hole closure.

According to the literature, small-gauge vitreoretinal surgery using $23 \mathrm{G}$ or $25 \mathrm{G}$ cannulated systems may be advantageous in reducing the incidence of sclerotomyassociated breaks and postoperative retinal detachment. ${ }^{37}$ Our data show that, compared to the $20 \mathrm{G}$ group, with the use of $23 \mathrm{G}$ instruments, the risk of intraoperative retinal tears could not be reduced. However, postoperative retinal detachments were only observed in the $20 \mathrm{G}$ group and never in the $23 \mathrm{G}$ group. This result might demonstrate the advantage of microincisional surgery in preventing postoperative retinal detachments, but the number of cases was too small for statistical testing.

Kryocoagulation and/or lasercoagulation was more frequently used in groups II and III than in groups I and IV. This result might show that non-experienced surgeons did not detect as much suspicious retinal regions as surgeons with a wider experience. According to these data, during the learning phase, more retinal defects might have been not only created but also seen and treated by medium experienced surgeons (groups II and III). Very experienced surgeons (group IV) probably created less tears and therefore had to treat less.

In our OCT findings, we did not detect any iatrogenic MHs. Since only 6 radial line scans with a scan size of $5,780 \mu \mathrm{m}$ were performed, small or eccentric iatrogenic MHs might have stayed unrevealed.

ICG has been suspected to cause retinal toxicity including apoptotic retinal cell death in vitro, optic nerve atrophy and persistent visual field defects with clinical studies reporting conflicting results. ${ }^{38-41} \mathrm{BBG}$ has been reported to be safe with minimal toxicity. ${ }^{42,43}$ However, our results do show a statistically significant trend for a better visual outcome in the group of eyes peeled by using BBG.

In total, functional long-term improvement in visual acuity (defined as an improvement of $>0.2 \log$ MAR) was achieved in $64 \%$ of the cases, ranging from $0.84 \log$ MAR before surgery to $0.45 \log$ MAR postoperatively, which is consistent with the findings of other studies. ${ }^{3,6,9}$

Nevertheless, surgeons with $\geq 6$ years of previous experience in vitreoretinal surgery achieved significantly better visual outcomes.

At first sight, this result could also be related to the use of ICG. Eyes treated with ICG instead of BBG for ILM peeling had worse postoperative visual outcome. In group I (0-3 years of experience in vitreoretinal surgery), in all cases, ICG was used for ILM peeling, in group IV (the group with $\geq 6$ years of experience) only 49 of 97 (50.5\%) eyes were peeled with ICG and another 48 of 97 (49.5\%) eyes were peeled with the help of BBG. Nevertheless, multivariate analyses including used dye, MH size, preoperative visual acuity and postoperative follow-up showed a statistically better visual outcome in group IV, indicating that differences between the groups concerning visual outcome were not depending only on the use of ICG.

Successful MH closure is not always associated with good visual rehabilitation. Several studies indicate that restoration of the outer retina plays a key role in good functional outcome. The reconstruction of the outer retina seems to be the better prognostic factor for a good postoperative visual improvement. ${ }^{21,31,44}$

Our results hint at a trend that restoration of the EZ is more frequently achieved according to the surgeon's experience, but the differences between the groups were not statistically significant.

\section{Conclusion}

Our data demonstrate that the only significant risk factor for non-closure was the size of the hole. Multivariate statistical analysis represented that all other risk factors had no influence on the anatomical outcome, whereas visual outcome after MH surgery correlated with the experience of the surgeon. It is possible that, during the surgeon's learning phase, the restoration and structure of the outer retina and the functional outcome have been negatively influenced by micro-traumata during the ILM peeling or by longer lasting exposure of the macular region to vital dyes.

Due to its retrospective design, this study has its limitations. The structure of the outer retina could not be sufficiently examined because of the short and also varying OCT follow-up periods. Visual field and near visual acuity testing would have been desirable but were not routinely performed in this investigation. Moreover, the individual experience of each surgeon and also the operation methods varied among the groups what is likely to have influenced the functional outcome.

However, our results show that surgeons performed well in $\mathrm{MH}$ surgery because of previous acquired surgical skills documented in a good closure rate and acceptable visual outcome. An additional study would be desirable to examine the visual field function and macular morphology in detail in eyes operated on MHs during the surgeon's learning phase.

\section{Disclosure}

The authors report no conflicts of interest in this work. 


\section{References}

1. La Cour M, Friis J. Macular holes: classification, epidemiology, natural history and treatment. Acta Ophthalmol Scand. 2002;80(6):579-587.

2. Jackson TL, Donachie PH, Sparrow JM, Johnston RL. United Kingdom National Ophthalmology Database study of vitreoretinal surgery: report 2, macular hole. Ophthalmology. 2012;120(3):629-634.

3. Kelly NE, Wendel RT. Vitreous surgery for idiopathic macular holes. Results of a pilot study. Arch Ophthalmol. 1991;109(5):654-659.

4. Gupta D. Face-down posturing after macular hole surgery: a review. Retina. 2009;29(4):430-443.

5. Benson WE, Cruickshanks KC, Fong DS, et al. Surgical management of macular holes: a report by the American Academy of Ophthalmology. Ophthalmology. 2001;108(7):1328-1335.

6. Tognetto D, Grandin R, Sanguinetti G, et al; Macular Hole Surgery Study Group. Internal limiting membrane removal during macular hole surgery: results of a multicenter retrospective study. Ophthalmology. 2006;113(8):1401-1410.

7. Christensen UC, Krøyer K, Sander B, et al. Value of internal limiting membrane peeling in surgery for idiopathic macular hole stage 2 and 3 . a randomised clinical trial. Br J Ophthalmol. 2009;93(8):1005-1015.

8. Haritoglou C, Gass CA, Schaumberger M, Gandorfer A, Ulbig MW, Kampik A. Long-term follow-up after macular hole surgery with internal limiting membrane peeling. Am J Ophthalmol. 2002;134(5):661-666.

9. Meng Q, Zhang S, Ling Y, Cui D, Jin Y. Long-term anatomic and visual outcomes of initially closed macular holes. Am J Ophthalmol. 2011;151(5):896-900.

10. Schaal S, Barr CC. Management of macular holes: a comparison of 1-year outcomes of 3 surgical techniques. Retina. 2009;29(8):1091-1096.

11. Itoh Y, Inoue M, Rii T, Hiraoka T, Hirakata A. Significant correlation between visual acuity and recovery of foveal cone microstructures after macular hole surgery. Am J Ophthalmol. 2012;153(1):111-119.

12. Gupta B, Laidlaw DA, Williamson TH, Shah SP, Wong R, Wren S. Predicting visual success in macular hole surgery. Br J Ophthalmol. 2009; 93(11):1488-1491.

13. Tranos P, Ghazi-Nouri S, Rubin G, Adams Z, Charteris D. Visual function and subjective perception of visual ability after macular hole surgery. Am J Ophthalmol. 2004;138(6):995-1002.

14. Tadayoni R, Gaudric A, Haouchine B, Massin P. Relationship between macular hole size and the potential benefit of internal limiting membrane peeling. Br J Ophthalmol. 2006;90(10):1239-1241.

15. Suda K, Hangai M, Yoshimura N. Axial length and outcomes of macular hole surgery assessed by spectral-domain optical coherence tomography. Am J Ophthalmol. 2011;151(1):118-127.

16. Wendel RT, Patel AC, Kelly NE, Salzano TC, Wells JW, Novack GD. Vitreous surgery for macular holes. Ophthalmology. 1993;100(11): 1671-1676.

17. Ryan EH, Gilbert HD. Results of surgical treatment of recent-onset full-thickness idiopathic macular holes. Arch Ophthalmol. 1994; 112(12):1545-1553.

18. Gander IC, Senn P, Lüthi M, Schipper I. Prognostic factors and results after surgical treatment of idiopathic macular holes, stage 2 and 3. Klin Monbl Augenheilkd. 2000;216(5):272-277.

19. Ip MS, Baker BJ, Duker JS, et al. Anatomical outcomes of surgery for idiopathic macular hole as determined by optical coherence tomography. Arch Ophthalmol. 2002;120(1):29-35.

20. Kang SW, Ahn K, Ham DI. Types of macular hole closure and their clinical implications. Br J Ophthalmol. 2003;87(8):1015-1019.

21. Chang YC, Lin WN, Chen KJ, et al. Correlation between the dynamic postoperative visual outcome and the restoration of foveal microstructures after macular hole surgery. Am J Ophthalmol. 2015; 160(1):100-106

22. Christmas NJ, Smiddy WE, Flynn HW. Reopening of macular holes after initially successful repair. Ophthalmology. 1998;105(10):1835-1838.

23. Paques M, Massin P, Blain P, Duquesnoy AS, Gaudric A. Long-term incidence of reopening of macular holes. Ophthalmology. 2000; 107(4):760-765. Discussion 766.
24. Scott IU, Moraczewski AL, Smiddy WE, Flynn HW, Feuer WJ. Longterm anatomic and visual acuity outcomes after initial anatomic success with macular hole surgery. Am J Ophthalmol. 2003;135(5):633-640.

25. Bhatnagar P, Kaiser PK, Smith SD, Meisler DM, Lewis H, Sears JE. Reopening of previously closed macular holes after cataract extraction. Am J Ophthalmol. 2007;144(2):252-259.

26. Guillaubey A, Malvitte L, Lafontaine PO, et al. Incidence of retinal detachment after macular surgery: a retrospective study of 634 cases. Br J Ophthalmol. 2007;91(10):1327-1330.

27. Passemard M, Yakoubi Y, Muselier A, et al. Long-term outcome of idiopathic macular hole surgery. Am J Ophthalmol. 2010;149(1): $120-126$.

28. Banker AS, Freeman WR, Kim JW, Munguia D, Azen SP. Visionthreatening complications of surgery for full-thickness macular holes. Vitrectomy for Macular Hole Study Group. Ophthalmology. 1997; 104(9):1442-1452. Discussion 1452-1453.

29. Briszi A, Prahs P, Hillenkamp J, Helbig H, Herrmann W. Complication rate and risk factors for intraoperative complications in residentperformed phacoemulsification surgery. Graefes Arch Clin Exp Ophthalmol. 2012;250(9):1315-1320.

30. Gass JD. Reappraisal of biomicroscopic classification of stages of development of macular hole. Am J Ophthalmol. 1995;119(6)752-759.

31. Ruiz-Moreno JM, Lugo F, Montero JA, Piñero DP. Restoration of macular structure as the determining factor for macular hole surgery outcome. Graefes Arch Clin Exp Ophthalmol. 2012;250(10):1409-1414.

32. Rahman R, Madgula I, Khan K. Outcomes of sulfur hexafluoride (SF6) versus perfluoroethane (C2F6) gas tamponade for non-posturing macular-hole surgery. Br J Ophthalmol. 2012;96(2):185-188.

33. Krohn J. Duration of face-down positioning after macular hole surgery: a comparison between 1 week and 3 days. Acta Ophthalmol Scand. 2005;83(3):289-292.

34. Blomquist PH, Rugwani RM. Visual outcomes after vitreous loss during cataract surgery performed by residents. J Cataract Refract Surg. 2002;28(5):847-852.

35. Chung SE, Kim K-H, Kang SW. Retinal breaks associated with the induction of posterior vitreous detachment. Am J Ophthalmol. 2009; 147(6):1012-1016.

36. Sjaarda RN, Glaser BM, Thompson JT, Murphy RP, Hanham A. Distribution of iatrogenic retinal breaks in macular hole surgery. Ophthalmology. 1995;102(9):1387-1392.

37. Krishnan R, Tossounis C, Fung Yang Y. 20-gauge and 23-gauge phacovitrectomy for idiopathic macular holes: comparison of complications and long-term outcomes. Eye (Lond). 2013;27(1):72-77.

38. Stanescu-Segall D, Jackson TL. Vital staining with indocyanine green: a review of the clinical and experimental studies relating to safety. Eye (Lond). 2009;23(3):504-518.

39. Kanda S, Uemura A, Yamashita T, Kita H, Yamakiri K, Sakamoto T. Visual field defects after intravitreous administration of indocyanine green in macular hole surgery. Arch Ophthalmol. 2004;122(10):1447-1451.

40. Yuen D, Gonder J, Proulx A, Liu H, Hutnik C. Comparison of the in vitro safety of intraocular dyes using two retinal cell lines: a focus on brilliant blue $\mathrm{G}$ and indocyanine green. Am J Ophthalmol. 2009; 147(2):251-259.

41. Yamashita T, Uemura A, Kita H, Sakamoto T. Analysis of the retinal nerve fiber layer after indocyanine green-assisted vitrectomy for idiopathic macular holes. Ophthalmology. 2006;113(2):280-284.

42. Remy M, Thaler S, Schumann RG, et al. An in vivo evaluation of Brilliant Blue $\mathrm{G}$ in animals and humans. Br J Ophthalmol. 2008;92(8): 1142-1147.

43. Kumar A, Gogia V, Shah VM, Nag TC. Comparative evaluation of anatomical and functional outcomes using brilliant blue $\mathrm{G}$ versus triamcinolone assisted ILM peeling in macular hole surgery in Indian population. Graefes Arch Clin Exp Ophthalmol. 2011;249(7):987-995.

44. Grewal DS, Reddy V, Mahmoud TH. Assessment of foveal microstructure and foveal lucencies using optical coherence tomography radial scans following macular hole surgery. Am J Ophthalmol. 2015; 160(5):990-999. 


\section{Publish your work in this journal}

Clinical Ophthalmology is an international, peer-reviewed journal covering all subspecialties within ophthalmology. Key topics include: Optometry; Visual science; Pharmacology and drug therapy in eye diseases; Basic Sciences; Primary and Secondary eye care; Patient Safety and Quality of Care Improvements. This journal is indexed on

Submit your manuscript here: http://www.dovepress.com/clinical-ophthalmology-journal
PubMed Central and CAS, and is the official journal of The Society of Clinical Ophthalmology (SCO). The manuscript management system is completely online and includes a very quick and fair peer-review system, which is all easy to use. Visit http://www.dovepress.com/ testimonials.php to read real quotes from published authors. 